\title{
Prevalence of Depression and Associated Factors among Medical Students in a Southern Nigerian University
}

\author{
Uzoechi Eze Chikezie $^{1} \&$ Tamaraemumoemi Emmanuella Okoro ${ }^{1}$ \\ ${ }^{1}$ Department of Internal Medicine, Niger Delta University Teaching Hospital, Okolobiri, Bayelsa State, Nigeria \\ Correspondence: Tamaraemumoemi Emmanuella Okoro, Consultant Cardiologist, Department of Internal \\ Medicine, Niger Delta University Teaching Hospital, Okolobiri, Bayelsa State, Nigeria. Tel: 234-080-3309-1319.
}

Received: January 29, 2021 Accepted: April 13, 2021 Online Published: November 2, 2021

doi:10.5539/gjhs.v13n12p12 URL: https://doi.org/10.5539/gjhs.v13n12p12

\begin{abstract}
Introduction: Medical students may be vulnerable to depression and other psychiatric morbidity. This study sought to assess the prevalence of depression and associated factors among medical students in Niger Delta University, Bayelsa State, Nigeria.

Methods: Using a self-administered, author-developed questionnaire with adaptations from the Patient-rated version of Mini-International Neuropsychiatric Interview (MINI-PR) and the Depression Anxiety Stress Scale (DASS), data including socio-demographic characteristics, alcohol use/abuse, cigarette smoking, features of depression and anxiety were collected from 243 medical students in this descriptive cross-sectional study over a period of 4 months.
\end{abstract}

Results: Of the 243 participants, $52.7 \%$ were male, mostly aged 18 to 24 years $(67.1 \%)$. The incidence of depression, suicidal ideation, alcohol use, and psychoactive substance use as defined by the MINI questionnaire was $30.5 \%, 14.8 \%, 14.8 \%$, and $9.9 \%$, respectively. As defined by DASS 21 , almost a third suffered different levels of anxiety (29.6\%), and less than one-fifth reported different levels of stress (17.7\%). Female gender and year of study showed a significant association with the diagnosis of depression $\left(X^{2}=15.75 ; \mathrm{p}-0.008\right)$. Living arrangement $\left(X^{2}=11.43 ; \mathrm{p}-0.022\right)$, perception of accommodation condition $\left(X^{2}=16.35 ; \mathrm{p}-0.001\right)$, academic performance $\left(X^{2}=18.02 ; \mathrm{p}-0.001\right)$, and experience of academic failure $\left(X^{2}=5.13 ; \mathrm{p}-0.023\right)$ all had a significant relationship with depression among the study population.

Conclusion: Prevalence of depression among medical students is high; its diagnosis showed a significant association with female gender, year of study, and perception of social and academic factors. Several comorbid psychiatric conditions may coexist with depression among medical students; therefore, the approach to their mental health should be holistic with attention paid to associated factors and psychiatric comorbidities.

Keywords: Depression, medical students, associated factors, psychiatric comorbidities

\section{Introduction}

Depression is a clinical condition characterized by a sad mood, reduction in energy levels and activity (anergia), loss of interest in pleasurable activities (anhedonia), sleep disturbances and pessimism, amongst others (Maj et al., 2020). It is also associated with an increased risk of suicide. It usually begins at a young age and runs a chronic, recurrent course with female preponderance (Marcus et al., 2020). Depression is among the leading causes of global morbidity and mortality, with a lifetime prevalence of about $5-10 \%$ in most countries. The World Health Organization estimates that about 350 million people suffer from depression globally. By 2020, it is estimated that depression will be the second most burdensome disease worldwide as measured by the Disability Adjusted Life Years (World Health Organization, 2001). It causes great suffering and economic loss to those affected and to society at large. There is also an increasing prevalence of depression among young people (Mojtabai et al., 2016; Juma et al., 2020). A comparison of mental health problems in higher education students in the United Kingdom of 2015/2016 with 2006/2007 found that the number of students disclosing mental health problems increased fivefold, and university deaths by suicide increased by $79 \%$ (Thorley, 2017).

Medical students are believed to be at increased risk of depression compared to other students and the general population (Dyrbye et al., 2014; Dyrbye et al., 2016). Studies from different parts of the world have shown an increased prevalence of depression among medical students (Puthran et al., 2016; Roh et al., 2010; Onyishi et al., 
2016). These range from 10-50\% across the various studies (Puthran et al., 2016; Roh et al., 2010; Onyishi et al., 2016; Singh et al., 2010; Ngasa et al., 2017; Nwobi et al., 2009). A study in India found 49.1\% of medical students were depressed, and with females and medical students in the first two years of study being the most affected (Singh et al., 2010). In Cameroon, Ngasa et al. (2017) noted that $30.6 \%$ of medical students in their study had depression. Nwobi et al. (2009) and Aniebue and Onyema (2008) reported a prevalence of $38.1 \%$ and $23.3 \%$ for depression among medical students in Nigeria. They found depression prevalence was higher among females and associated with examination failures, irregular lectures, inadequate accommodation, academic stress, parental pressures, and financial difficulties (Nwobi et al., 2009; Aniebue \& Onyema 2008). Depression has also been linked to elevated stress, sleep deprivation, substance use, and suicidality among different groups of medical students (Dyrbye et al., 2014; Onyishi et al., 2016; Aniebue \& Onyema, 2008). Several studies report higher depression and stress among students in the first and second years of study, possibly because they are new in the system and still adjusting to the academic pressure (Roh et al., 2010; Onyishi et al., 2016).

Depression among medical students should be of significant concern to all because such may lead to poor academic and clinical performance and sometimes continue until they graduate as medical doctors. The consequences could include poor productivity, medical errors, and attendant negative outcomes associated with "the impaired Physician." (Bulent et al., 2017) It is therefore important to investigate depression among medical students with a view to early detection and proffering possible solutions. This becomes even more relevant in developing countries like Nigeria with scanty information on this subject.

Most previous studies assessing depression in medical students and medical doctors made use of less validated instruments (Onyishi et al., 2016; Nwobi et al., 2009; Aniebue \& Onyema, 2008; Falade et al., 2020; Issa et al., 2014; Pettersson et al., 2015). In an analysis of twenty instruments frequently used in case finding, diagnosis, and severity grading of major depression, only the Structured Clinical Interview for DSMIV-Axis-I Disorders (SCID-I), Mini International Neuropsychiatric Interview (MINI), and Patient Health Questionnaire-9 (PHQ-9) fulfilled the minimum criteria for sensitivity and specificity (Pettersson et al., 2015). This study was conceptualized to assess the prevalence of depression and associated factors among medical student populations in Niger Delta University, Bayelsa State, Nigeria using diagnostic and widely validated instruments.

\section{Materials and Methods}

\subsection{Study Area}

The study conducted was carried out at the pre-clinical lecture theatre of the College of Health Sciences, Niger Delta University (NDU), Amassoma, and also the lecture rooms of the Niger Delta University Teaching Hospital Okolobiri (NDUTH), all in Bayelsa State, Nigeria. The NDU is located at Amassoma in Bayelsa state. The state is located in the heart of the oil-rich Niger Delta region and the South-South geopolitical zone, sharing a boundary with the Atlantic Ocean. It is riverine and mainly inhabited by the Ijaw tribe but also home to other Nigerians and foreigners. The university shows such diversity in its students' population also. The NDUTH is located at Okolobiri community which is about 20 minutes' drive from Yenagoa, the state capital. It renders specialized clinical care to residents of Bayelsa state and neighboring states. It also serves as a center for clinical training and research. The pre-clinical students were studied at the pre-clinical lecture theatres Amassoma, while the clinical students were studied in the lecture rooms of the NDUTH Okolobiri (NDU, 2020).

\subsection{Study Design}

The study was a descriptive cross-sectional study. Data collection occurred for a duration of 4months between August and November 2018.

\subsection{Study Population}

The study involved all medical students at all levels of study (clinical and pre-clinical) that gave informed consent to be part of the study. Only students who give voluntary consent were recruited for the study.

\subsection{Sample Size}

We calculated sample size using the formula for estimation of proportion (Eng, J. 2003)stated below with the prevalence of depression in Nigeria (23.3\%) as reported by Anibue et al., 2008, this gave a value of 275 participants.

$$
N=\frac{Z^{2} P Q}{d^{2}}
$$

where $\mathrm{N}=$ number of participants, $\mathrm{Z}=1.96, \mathrm{P}=$ prevalence $(23.3 \%$ or 0.233$)$ and $\mathrm{D}=0.05$. However, the above 
estimated minimum sample size is true for populations greater than 10,000. The total population of medical students in the university was estimated to be about three hundred students, with an average of fifty students in each grade of student. Therefore, the sample size is adjusted using a correction formula for desired sample size calculation when a population is less than 10,000 (Bartlett et al., 2001; Mahajan et al., 2010). This is expressed as:

$$
n=\frac{N_{0}}{1+\frac{N_{0}-1}{N}}
$$

where, $\mathrm{n}=$ adjusted sample size; $\mathrm{N}_{0}=$ sample size estimate for population size greater than 10,000 (275); $\mathrm{N}=$ Total population of persons with the variable of interest who are the medical students (300 students). Substitution yielded a minimum sample size of 143 participants for the study. We also corrected for non-response using a non-response rate of $20 \%$. The $20 \%$ of 143 is approximately 29 ; hence the final minimum sample size of 172 was obtained for the study. However, we eventually sampled a total of 243 medical students at NDU.

\subsection{Sampling Technique}

A probability sampling technique, simple random sampling (balloting) was deployed to recruit participants from each level of study. The number on the class attendance register was used to represent each member's unique identifier for the study.

\subsection{Study Instrument}

The study instrument for this study was a 3-section questionnaire developed by the researchers with a total of 82 items comprising of different validated tools which have been used in different settings to assess depression and associated factors. Section One of the study tool collected data on socio-demographic characteristics, level of study, living arrangement, accommodation conditions, socioeconomic class, financial pressure, and academic performance of participants. Section Two contained the Patient-rated version of Mini-International Neuropsychiatric Interview (MINI-PR) (Roh et al., 2010, Sheehan et al., 1998, Aguocha et al., 2015) exploring features of depression, suicidal ideation, alcohol, and substance use/abuse. This was used to diagnose depression among participants. The Depression Anxiety Stress Scale (DASS) investigates the levels of stress and anxiety among participants and forms the Section Three of the study tool. These instruments have been widely used and validated in the assessment of depression, substance/alcohol use and abuse, anxiety, and stress in our locality ((Roh et al., 2010; Sheehan et al., 1998; Aguocha et al., 2015; Lovibond et al., 1995; Oladiji et al. 2009).

\subsection{Study Procedure}

Two trained research assistants in collaboration with the two principal investigators collected data for the study. The research assistants were recruited from medical officers working in the Internal medicine department of the Niger Delta University Teaching Hospital (NDUTH). The training involved explaining the different items on the questionnaire to the research assistants to ensure they understood the response each item on the questionnaire was designed to elicit. The objectives and procedure for sampling and seeking consent for the study were also enumerated during the training. Before the data collection proper, the various class representatives were intimated with the objectives, purpose, and benefit of the study, hence their support was secured, and they helped organize class members who had the questionnaire administered to them during their breaks.

The questionnaires were given to the recruited members of each class to self-administer it on themselves. On the return of the questionnaire, each questionnaire was cross-checked to make sure it was properly filled. Each questionnaire took no more than 15 minutes to complete. Research assistants who had been trained by the authors and the authors themselves were available to assist participants where necessary in filling the questionnaires. Anonymity and confidentiality were upheld. The questionnaires were pretested prior to the commencement of the study at the University of Benin among 3rd year medical students to further ensure the reliability and validity of the questionnaire.

\subsection{Data Analysis}

Data were analyzed using the Statistical Package for Social Sciences version 23 (SPSS 23) (Bryman \& Cramer 2013). Categorical variables were summarized in frequencies and percentages, and relationships between socio-demographic characteristics, financial pressure, living arrangement, academic performance, and depression were explored using the Chi-square tests of proportion. The level of significance was set at $\leq 0.05$ (at $95 \%$ Confidence Interval). 


\subsection{Ethical Issues}

The study was conducted in accordance with the Helsinki declaration, (World Medical Association Declaration of Helsinki. 2013) and ethical clearance was obtained from the Research and Ethics committee of the Niger Delta University Teaching Hospital. Voluntary written informed consent was obtained from the study participants. All data was handled with strict confidentiality.

\section{Results}

\subsection{Socio-Demographic Characteristics of Participants}

Of the 243 participants in the study, $52.7 \%$ were male medical students, and most were aged 18 to 24 years (67.1\%), single (94.2\%), Christian (97.5\%), and in the first year of study (24.3\%).

Table 2 revealed that most students live in the hostel $(42.0 \%)$ and consider their accommodation conditions fair (49.0\%). About half think they suffer moderate financial pressure. While $43.2 \%$ of the study population considers their academic performance of average standard, about a third has experienced academic failure in medical school $(32.9 \%)$.

\subsection{Prevalence of Depression, Suicidal ideation, Alcohol, and Psychoactive Substance Use}

Table 3 shows that the incidence of depression, suicidal ideation, alcohol use, and psychoactive substance use as defined by the MINI questionnaire is $30.5 \%, 14.8 \%, 14.8 \%$, and $9.9 \%$, respectively. The incidence of other classifications of these medical conditions is shown in Table 3.

Table 4 highlights the incidence of depression, anxiety, and stress as defined by the DASS 21 questionnaire. Depression as defined by DASS 21 is seen in about a quarter of participants, while almost a third suffer different level of anxiety (29.6\%), less than one-fifth reported different levels of stress (17.7\%).

\subsection{Relationship between Depression and Independent Variables in the Study}

Table 5 shows the relationship between depression and socio-demographic characteristics of the study participants. Female gender and the year of study show a significant association with the diagnosis of depression $\left(X^{2}=3.80 ; \mathrm{p}-\right.$ $0.051, X^{2}=15.75 ; \mathrm{p}-0.008$, respectively).

Table 6 reveals that living arrangement $\left(X^{2}=11.43 ; \mathrm{p}-0.022\right)$, perception of accommodation condition $\left(X^{2}=\right.$ $16.35 ; \mathrm{p}-0.001)$, academic performance $\left(X^{2}=18.02 ; \mathrm{p}-0.001\right)$ and experience of academic failure $\left(X^{2}=5.13 ; \mathrm{p}-\right.$ 0.023 ) all have significant relationship with depression among the study population.

Table 1. Sociodemographic characteristics of study participants

\begin{tabular}{|c|c|c|}
\hline Characteristics & Frequency $(n=243)$ & Percent (\%) \\
\hline \multicolumn{3}{|l|}{ Sex } \\
\hline Female & 115 & 47.3 \\
\hline Male & 128 & 52.7 \\
\hline \multicolumn{3}{|l|}{ Age group } \\
\hline $18-24$ years & 163 & 67.1 \\
\hline $25-29$ years & 51 & 21.0 \\
\hline $30-34$ years & 15 & 6.2 \\
\hline$\geq 35$ years & 14 & 5.8 \\
\hline \multicolumn{3}{|l|}{ Religion } \\
\hline Christian & 237 & 97.5 \\
\hline Others & 6 & 2.5 \\
\hline \multicolumn{3}{|l|}{ Marital Status } \\
\hline Married & 14 & 5.8 \\
\hline Single & 229 & 94.2 \\
\hline \multicolumn{3}{|l|}{ Socioeconomic status } \\
\hline High & 10 & 4.1 \\
\hline
\end{tabular}




\begin{tabular}{crc}
\hline Middle & 193 & 79.4 \\
Low & 40 & 16.5 \\
\hline Level of Study & 59 & 24.3 \\
100 & 26 & 10.7 \\
200 & 35 & 14.4 \\
300 & 47 & 19.3 \\
400 & 25 & 10.3 \\
500 & 51 & 21.0 \\
600 & & \\
\hline
\end{tabular}

Table 2. Distribution of conditions that can trigger depression among study participants

\begin{tabular}{|c|c|c|}
\hline Characteristics & Frequency $(n=243)$ & Percent (\%) \\
\hline \multicolumn{3}{|l|}{ Living arrangement } \\
\hline Live alone & 60 & 24.7 \\
\hline Live with Student & 21 & 8.6 \\
\hline Live with Parents & 10 & 4.1 \\
\hline Live in Hostel & 102 & 42.0 \\
\hline Live outside & 50 & 20.6 \\
\hline \multicolumn{3}{|c|}{ Perception of Accommodation condition } \\
\hline Satisfactory & 90 & 37.0 \\
\hline Just fair & 119 & 49.0 \\
\hline Unsatisfactory & 31 & 12.8 \\
\hline Deplorable & 3 & 1.2 \\
\hline \multicolumn{3}{|l|}{ Financial Pressure } \\
\hline High & 58 & 23.9 \\
\hline Moderate & 129 & 53.1 \\
\hline Low & 32 & 13.2 \\
\hline None & 24 & 9.9 \\
\hline \multicolumn{3}{|l|}{ Academic Performance } \\
\hline Excellent & 16 & 6.6 \\
\hline Good & 116 & 47.7 \\
\hline Average & 105 & 43.2 \\
\hline Below average & 3 & 1.2 \\
\hline Poor & 3 & 1.2 \\
\hline \multicolumn{3}{|c|}{ Have you experienced Academic failure in the Medical School? } \\
\hline No & 163 & 67.1 \\
\hline Yes & 80 & 32.9 \\
\hline
\end{tabular}


Table 3. Depression, Suicidality, Alcohol and Psychoactive substance use disorder as classified by MINI Scale

\begin{tabular}{lcc}
\hline Characteristics & Frequency $(\mathbf{n}=\mathbf{2 4 3})$ & Percent (\%) \\
\hline Depression & 74 & 30.5 \\
$\quad$ Major Depressive Episode, Current & 70 & 28.8 \\
Major Depressive Episode, Recurrent & 65 & 26.7 \\
$\quad$ Depression with Melancholic features & & \\
\hline Suicidality & 36 & 14.8 \\
$\quad$ Suicide ideation & & \\
Suicide Risk, Current & 207 & 85.2 \\
$\quad$ No risk & 27 & 11.1 \\
$\quad$ Low risk & 5 & 2.1 \\
$\quad$ Moderate risk & 4 & 1.6 \\
$\quad$ High risk & & 14.8 \\
\hline Alcohol Abuse and Dependence & 36 & 5.8 \\
Alcohol Use & 14 & 4.9 \\
Alcohol abuse, current & 12 & \\
Alcohol dependence, current & & 9.9 \\
\hline Psychoactive Substance Use Disorder & 24 & 5.3 \\
Psychoactive substance Use & 13 & 3.7 \\
Psychoactive substance use disorder & 9 & 2.1 \\
Psychoactive substance use Abuse & 5 & \\
Psychoactive substance use Dependence & & \\
\end{tabular}

Table 4. Depression, Anxiety and Stress as classified by DASS 21

\begin{tabular}{lcc}
\hline Characteristics & Frequency $\mathbf{( n = 2 4 3 )}$ & Percent (\%) \\
\hline Depression & 181 & 74.5 \\
Normal & 26 & 10.7 \\
Mild Depression & 15 & 6.2 \\
Moderate Depression & 9 & 3.7 \\
Severe Depression & 12 & 4.9 \\
Extreme Severe Depression & & \\
\hline Anxiety & 171 & 70.4 \\
Normal & 13 & 5.3 \\
Mild Anxiety & 28 & 11.5 \\
moderate Anxiety & 12 & 4.9 \\
Severe Anxiety & 19 & 7.8 \\
Extreme Severe Anxiety & & \\
\hline Stress & 200 & 82.3 \\
Normal & 16 & 6.6 \\
Mild Stress & 11 & 4.5 \\
Moderate Stress & 10 & 4.1 \\
Severe Stress & 6 & 2.5 \\
Extreme Severe Stress & &
\end{tabular}


Table 5. Relationship between depression and Socio-demographic characteristics of Study participants

\begin{tabular}{|c|c|c|c|c|c|c|}
\hline \multirow[b]{2}{*}{ Characteristics } & \multicolumn{3}{|c|}{ Depression } & \multirow[b]{2}{*}{$X^{2}$} & \multirow[b]{2}{*}{ df } & \multirow[b]{2}{*}{ pValue } \\
\hline & $\begin{array}{l}\text { Total } \\
N=243(\%)\end{array}$ & $\begin{array}{l}\text { Yes } \\
N=74(\%)\end{array}$ & $\begin{array}{l}\text { No } \\
N=169(\%)\end{array}$ & & & \\
\hline \multicolumn{7}{|l|}{ Sex } \\
\hline Female & $115(47.3)$ & $42(56.8)$ & $73(43.2)$ & 3.80 & 1 & 0.051 \\
\hline Male & $128(52.7)$ & $32(43.2)$ & $96(56.8)$ & & & \\
\hline \multicolumn{7}{|l|}{ Age group } \\
\hline 18 - 24 years & $163(67.0)$ & $57(77.0)$ & $106(62.7)$ & 5.97 & 3 & 0.113 \\
\hline $25-29$ years & $51(21.0)$ & $13(17.6)$ & $38(22.5)$ & & & \\
\hline $30-34$ years & $15(6.2)$ & $2(2.7)$ & $13(7.7)$ & & & \\
\hline$\geq 35$ years & $14(5.8)$ & $2(2.7)$ & $12(7.1)$ & & & \\
\hline \multicolumn{7}{|l|}{ Religion } \\
\hline Christian & $237(97.5)$ & $72(97.3)$ & $165(97.6)$ & 0.02 & 1 & 0.877 \\
\hline Others & $6(2.5)$ & $2(2.7)$ & $4(2.4)$ & & & \\
\hline \multicolumn{7}{|l|}{ Marital Status } \\
\hline Married & $14(5.8)$ & $2(2.7)$ & $12(7.1)$ & 1.83 & 1 & 0.176 \\
\hline Single & $229(94.2)$ & $72(97.3)$ & $157(92.9)$ & & & \\
\hline \multicolumn{7}{|c|}{ Socioeconomic status } \\
\hline High & $10(4.1)$ & $3(4.1)$ & $7(4.1)$ & 2.07 & 2 & 0.344 \\
\hline Middle & $193(79.4)$ & $55(74.3)$ & $138(81.7)$ & & & \\
\hline Low & $40(16.5)$ & $16(21.6)$ & $24(14.2)$ & & & \\
\hline \multicolumn{7}{|l|}{ Level of Study } \\
\hline 100 & $59(24.3)$ & $20(27.0)$ & $39(23.1)$ & 15.75 & 5 & $0.008^{*}$ \\
\hline 200 & $26(10.7)$ & $16(21.6)$ & $10(5.9)$ & & & \\
\hline 300 & $35(14.4)$ & $10(13.5)$ & $25(14.8)$ & & & \\
\hline 400 & $47(19.3)$ & $11(14.9)$ & $36(21.3)$ & & & \\
\hline 500 & $25(10.3)$ & $6(8.1)$ & $19(11.2)$ & & & \\
\hline 600 & $51(21.0)$ & $11(14.9)$ & $40(23.7)$ & & & \\
\hline
\end{tabular}

Table 6. Relationship between depression and perception of social and academic factors

\begin{tabular}{|c|c|c|c|c|c|c|}
\hline \multirow[b]{2}{*}{ Characteristics } & \multirow[b]{2}{*}{$\begin{array}{l}\text { Total } \\
N=\mathbf{2 4 3}(\%)\end{array}$} & \multicolumn{2}{|l|}{ Depression } & \multirow[b]{2}{*}{$X^{2}$} & \multirow[b]{2}{*}{ df } & \multirow[b]{2}{*}{ pValue } \\
\hline & & $\begin{array}{l}\text { Yes } \\
\mathrm{N}=74(\%)\end{array}$ & $\begin{array}{l}\text { No } \\
N=169(\%)\end{array}$ & & & \\
\hline \multicolumn{7}{|l|}{ Living arrangement } \\
\hline Live alone & $60(24.7)$ & $13(17.6)$ & $47(27.8)$ & 11.43 & 4 & $0.022 *$ \\
\hline Live with Student & $21(8.6)$ & $10(13.5)$ & $11(6.5)$ & & & \\
\hline Live with Parents & $10(4.1)$ & $4(5.4)$ & $6(3.6)$ & & & \\
\hline Live in Hostel & $102(42.0)$ & $38(51.4)$ & $64(37.9)$ & & & \\
\hline Live outside & $50(20.6)$ & $9(12.2)$ & $41(24.3)$ & & & \\
\hline \multicolumn{7}{|c|}{ Perception of Accommodation condition } \\
\hline Satisfactory & $90(37.0)$ & $20(27.0)$ & $70(41.4)$ & 16.35 & 3 & $0.001 *$ \\
\hline Fair & $119(49.0)$ & $35(47.3)$ & $84(49.7)$ & & & \\
\hline Unsatisfactory & $31(12.8)$ & $16(21.6)$ & $15(8.9)$ & & & \\
\hline Deplorable & $3(1.2)$ & $3(4.1)$ & $0(0.0)$ & & & \\
\hline
\end{tabular}




\begin{tabular}{|c|c|c|c|c|c|c|}
\hline \multicolumn{7}{|c|}{ Financial Pressure } \\
\hline High & $58(23.9)$ & $20(27.0)$ & $38(22.5)$ & 3.45 & 3 & 0.327 \\
\hline Moderate & $129(53.1)$ & $36(48.6)$ & $93(55.0)$ & & & \\
\hline Low & $32(13.2)$ & $13(17.6)$ & $19(11.2)$ & & & \\
\hline None & $24(9.9)$ & $5(6.8)$ & $19(11.2)$ & & & \\
\hline \multicolumn{7}{|c|}{ Academic Performance } \\
\hline Excellent & $16(6.6)$ & $2(2.7)$ & $14(8.3)$ & 18.02 & 4 & $0.001^{*}$ \\
\hline Good & $116(47.7)$ & $30(40.5)$ & $86(50.9)$ & & & \\
\hline Average & $105(43.2)$ & $36(48.6)$ & $69(40.8)$ & & & \\
\hline Below average & $3(1.2)$ & $3(4.1)$ & $0(0.0)$ & & & \\
\hline Poor & $3(1.2)$ & $3(4.1)$ & $0(0.0)$ & & & \\
\hline \multicolumn{7}{|c|}{ Have you experienced Academic failure in the Medical School? } \\
\hline No & $163(67.1)$ & $42(56.8)$ & $121(71.6)$ & 5.13 & 1 & $0.023^{*}$ \\
\hline Yes & $80(32.9)$ & $32(43.2)$ & $48(28.4)$ & & & \\
\hline
\end{tabular}

\section{Discussion}

Stressors such as higher academic requirements, social and emotional adjustments, new found independence, socioeconomic challenges, and time management pressure may be associated with university learning (Mutambara \& Bhebe, 2012, Rice, 2009). Medical students, in particular, are typically faced with these and several other challenges, including; a large academic workload, several qualifying examinations that determine whether or not they proceed to clinical classes, in addition to the pressures of the clinical environment (Moir et al., 2018; Brazeau et al., 2014; Oku \& Owoaje, 2015; Martin, 1997; Sreeramareddy et al., 2007; Gureje et al., 2006). The present study found that major depressive episodes, suicidal ideation, alcohol use, and psychoactive substance use among medical students were $30.5 \%, 14.8 \%, 14.8 \%$, and $9.9 \%$, respectively, as defined by the MINI questionnaire among study participants. The patient-rated version of Mini International Neuropsychiatric Interview (MINI-PR) used to diagnose depression among participants in this study is widely used and validated instrument (Puthran et al., 2016; Sheehan et al., 1998; Aguocha et al., 2015).

The incidence of major depressive episodes (MDE) in the medical students in this study is at least ten times higher than the general population (Gureje et al., 2006) with results from the Nigerian Survey of Mental Health and Well-being (2002/2003) showing lifetime and 12-month estimates of MDE of 3.1\% and 1.1\% respectively in the general population (Gureje et al., 2006) and the MDE found to be highly comorbid with anxiety disorder. A review of studies from 1990 and 2010 reporting on depression prevalence among university students suggests they experience rates of depression substantially higher than those found in the general population with reported prevalence rates ranging from $10 \%$ to $85 \%$ with a weighted mean prevalence of $30.6 \%$ (Ibrahim et al., 2013). A recent meta-analysis showed depression affected approximately a third of medical students worldwide, and other psychological difficulties, such as anxiety, suicidal thoughts, burnout, and substance abuse, may accompany depressive symptoms in these students (Rotenstein et al., 2016). This is similar to findings in the present study, which showed almost a third of the medical students suffered different levels of anxiety (29.6\%) while less than one-fifth reported different levels of stress (17.7\%) as defined by DASS 21 .

A comparison of mental health problems in higher education students in the UK of 2015/2016 with 2006/2007 found that the number of students disclosing mental health problems increased fivefold, and university deaths by suicide increased by $79 \%$ (Thorley 2017). Medical students are required to assimilate tremendous amounts of information, spend more years in training than their peers in most other disciplines, recall information from prior courses and score high grades in continuous assessments and examinations (Rotenstein et al., 2016). Some may struggle with the large medical curriculum, and these pressures may result in psychiatric morbidities (Falade et al. 2020). The present study found that perception of academic performance and the experience of academic failure had significant relationships with depression among the study population. This finding is similar to previous studies in both medical and non-medical students (Nwobi et al., 2009; Aniebue \& Onyema, 2008; Falade et al., 2020; Khan et al., 2018).' Falade et al. 2020 in a study involving 944 medical students found a $25.0 \%$ prevalence of psychiatric morbidity among the respondents, and associated independent factors also included; being a student of a private institution, average academic performance, and below-average academic performance. Using a 
cross-sectional design, Khan et al. (2018) collected data on several stressors psychiatric morbidities from 379 students. The stressors included workload, emotional and interpersonal demands, while the psychiatric morbidities included depression, anxiety, and social dysfunction. They found the perceived stressors and symptoms of mental illness were negatively related to the students' academic performance.

Living arrangements and perception of accommodation conditions were also significantly associated with depression. Our findings are also similar to previous findings by Nwobi et al. (2009); and Aniebue, and Onyema (2008) who also found depression prevalence was also associated with the perception of inadequate accommodation. Research shows satisfaction with one's living environment provides a buffer against poor mental health in everyday life, while dissatisfaction with accommodation/living arrangement can pose a significant risk to a person's mental health (World Health Organization \& Calouste Gulbenkian Foundation, 2014).

In assessing the relationship between depression and socio-demographic characteristics of the study participants, both female gender and year of the study show a significant association with the diagnosis of depression. Similar to our study, which found depression was common in the lower classes, several studies report higher depression and stress among students in the lower classes, especially the first and second years of study (Roh et al., 2010; Onyishi et al., 2016; Zoccolillo et al., 2006; Basnet et al., 2012) possibly because they are new in the system and still adjusting to the academic pressure. In a survey carried out among the undergraduate medical students in Nepal (Basnet et al. 2012), the prevalence of depression in the first and third year was 36.74 and 22.22 percent, respectively. Both the first and third-year students attributed mostly academic stress and a hectic lifestyle as the major stress-inducing factors (Zoccolillo et al., 2006). However, students are likely to learn to adopt active coping strategies such as positive framing, leisure activities, talking to family and friends, and exercising (Pierceall et al., 2007; Bamuhair et al., 2015) to deal with stress, by their final year of medical school than in earlier years (Puthran et al., 2016).

Contrary to this, some researchers suggest that the mental health of medical students' declines with increasing years of study and continues to decline as trainees enter the workforce (Aguocha et al., 2015). A meta-analysis by Dyrbye et al2005 showed that medical students at the start of medical school have similar mental health profile as their non-medical peers (Dyrbye et al., 2005; Carson et al., 2000). The decline in higher years and even post qualification decline may be attributable to various sources of stress, some of which include the increased academic workload, concern for academic performance, and the pressure of several qualifying examinations that determine academic and career progression (Sheehan et al., 1998; Guthrie et al., 1995; Cohen et al., 2005).

Similar to our findings, several studies show gender differences in the diagnosis of depression, with female medical students experiencing more depression than males (Singh et al., 2010; Nwobi et al., 2009; Aniebue \& Onyema, 2008; Dahlin et al., 2005, Ibrahim et al., 2015). The trend that females medical students experience more depression than males may be because they tend to be more concerned about working hard to secure higher marks in exams, are more competitive and concerned about their academic performance, may exaggerate their sadness, and tend to be less engaging with exercise (Inam et al., 2003; Zaid et al., 2007).

The incidence of suicidal ideation among medical students in the present study was $14.8 \%$. Suicidal ideation refers to thoughts about suicide, that may deliberately be constructed to fail or be discovered or may fully be intended to succeed (Aqeel et al., 2014). Globally, suicide is among the top three leading causes of death in men and women aged 15 - 44 years, accounting for nearly one million deaths annually (van Niekerk et al. 2012). This represents an annual age-standardized suicide rate of 11.4 per 100000 population globally and 6.11 per 100000 population for Nigeria (Adewuya et al., 2016). A previous study in the general population in Lagos, Nigeria showed a 7.28\% prevalence of suicidal ideation with independently associated factors being older age, female, single status, low socioeconomic status, depression, somatic symptoms, anxiety, and disability (Schernhammer, 2005). Prevalence of suicidal ideation and suicidal attempt tends to be at least 2-10 times higher in medical students compared to age matched general population (World Health Report, 2003; WHO Mortality Database Documentation May 2013. Medical students have a higher risk of suicidal ideation, suicide, burnout, and a lower quality of life than age-matched populations (World Health Report, 2003; Ayala et al., 2017; Jahrami et al., 2019; Jahrami et al., 2020).

\subsection{Limitations}

Responses depend on the truthfulness of the respondents.

\section{Conclusion}

The prevalence of depression among medical students is high. It is more prevalent in the lower (entry classes) medical classes and in female students. Several comorbid psychiatric conditions may also coexist with depression 
in medical students, and approach to their mental health should be holistic with attention also paid to associated factors and psychiatric comorbidities.

\section{Data Sharing Statement}

The datasets analyzed during the current study are available from the corresponding author on reasonable request.

\section{Acknowledgments}

The authors are grateful to all the medical students who consented to be part of the study

\section{Authors' Contributions}

EUC designed the study, wrote the protocol, and managed the statistical analysis, while TEO and EUC both contributed to writing the final manuscript. All authors contributed toward data analysis, drafting and revising the paper and agree to be accountable for all aspects of the work.

\section{Funding}

The study was self-funded

\section{Competing Interests Statement}

The authors declare that there are no competing or potential conflicts of interest.

\section{References}

Adewuya, A.O., Ola, B.A., Coker, O.A., Atilola, O., Zachariah, M.P., Olugbile, O., \& Idris, O. (2016). Prevalence and associated factors for suicidal ideation in the Lagos State Mental Health Survey, Nigeria. BJ Psych Open, 2, 385-389. https://doi.org/10.1192/bjpo.bp.116.004333

Aqeel, K., Mohamed, S. M., Abdul, R. H., \& Roslee, A. (2014). Influence of psychological factors on suicide ideation among Malaysian and Indian adolescents. Social and Behavioural Science, 143, 341-351. https://doi.org/10.1016/j.sbspro.2014.07.418

Aniebue, P. N., \& Onyema, G. O. (2008). Prevalence of depressive symptoms among Nigerian medical undergraduates. Trop Doct, 38, 157-8. https://doi.org/10.1258/td.2007.070202

Ayala, E. E., Roseman, D., Winseman, J. S., \& Mason, H. R. C. (2017) Prevalence, consequences, and perceptions of alcohol and drug use of U.S. medical students. Med Educ Online, 22, 1-7. https://doi.org/10.1080/10872981.2017.1392824

Bamuhair, S. S., Farhan, A. I., Althubaiti, A., Agha, S., Rahman, S., \& Ibrahim, N. (2015). Sources of stress and coping strategies among undergraduate medical students enrolled in a problem-based learning curriculum. $J$ Biomed Educ, 2015, 8. https://doi.org/10.1155/2015/575139

Bartlett, J. E., Kotrlik, J. W., \& Higgins, C. C. (2001). Organizational research: Determining appropriate sample size in survey research appropriate sample size in survey research. Information technology, learning, and performance journal, 19(1), 43.

Basnet, B., Jaiswal, M., Adhikari, B., Shyangwa, P.M. (2012). Depression among Undergraduate Medical Students. Medical Education, 10(39), 57-60. https://doi.org/10.3126/kumj.v10i3.8021

Brazeau, C. M. L. R., Shanafelt, T., Durning, S. J., Massie, F. S., Eacker, A., Moutier, C., \& Dyrbye, L.N. (2014). Distress among matriculating medical students relative to the general population. Acad Med, 89, 1520-5. https://doi.org/10.1097/ACM.0000000000000482

Bryman, A., \& Cramer, D. (2013). Quantitative Data Analysis with IBM SPSS 17, 18 and 19. A Guide for Social Scientists. New York: Routledge.

Bulent, E., Alis, O., \& Nazan, B. (2017). Depression and anxiety among medical students: Examining scores of the beck depression and anxiety inventory and the depression anxiety and stress scale with student characteristics. Cogent Psychology, 4(1), 1283829. https://doi.org/10.1080/23311908.2017.1283829

Carson, A. J., Dias, S., Johnston, A., McLoughlin, M. A., O'connor, M., Robinson, B. L., ... \& Wojcik, W. (2000). Mental health in medical students a case control study using the 60 item general health questionnaire. Scottish medical journal, 45(4), 115-116. https://doi.org/10.1177/003693300004500406

Cohen, J. S., \& Patten, S. (2005). Well-being in residency training: a survey examining resident physician satisfaction both within and outside of residency training and mental health in Alberta. BMC medical education, 5(1), 1-11. https://doi.org/10.1186/1472-6920-5-21 
Dahlin, M., Joneborg, N., \& Runeson, B. (2005). Stress and depression among medical students: A crosssectional study. Medical education, 39(6), 594-604. https://doi.org/10.1111/j.1365-2929.2005.02176.x

Dyrbye, L. N., Thomas, M. R., \& Shanafelt, T. D. (2005, December). Medical student distress: causes, consequences, and proposed solutions. In Mayo Clinic Proceedings (Vol. 80, No. 12, pp. 1613-1622). Elsevier. https://doi.org/10.4065/80.12.1613

Dyrbye, L. N., Thomas, M. R., \& Shanafelt, T. D. (2006). Systematic review of depression, anxiety, and other indicators of psychological distress among US and Canadian medical students. Academic medicine, 81(4), 354-373. https://doi.org/10.1097/00001888-200604000-00009

Dyrbye, L. N., West, C. P., Satele, D., Boone, S., Tan, L., Sloan, J., \& Shanafelt, T. D. (2014). Burnout among US medical students, residents, and early career physicians relative to the general US population. Academic medicine, 89(3), 443-451. https://doi.org/10.1097/ACM.0000000000000134

Eng, J. (2003). Sample size estimation: how many individuals should be studied?. Radiology, 227(2), $309-313$. https://doi.org/10.1148/radiol.2272012051

Falade, J., Oyebanji, A. H., Babatola, A. O., Falade, O. O., \& Olumuyiwa, T. O. (2020). Prevalence and correlates of psychiatric morbidity, comorbid anxiety and depression among medical students in public and private tertiary institutions in a Nigerian state: a cross-sectional analytical study. The Pan African Medical Journal, 37. https://doi.org/10.11604/pamj.2020.37.53.24994

Gureje, O., Lasebikan, V. O., Kola, L., \& Makanjuola, V. A. (2006). Lifetime and 12-month prevalence of mental disorders in the Nigerian Survey of Mental Health and Well-Being. The British Journal of Psychiatry, 188(5), 465-471. https://doi.org/10.1192/bjp.188.5.465

Guthrie, E. A., Black, D., Shaw, C. M., Hamilton, J., Creed, F. H., \& Tomenson, B. (1995). Embarking upon a medical career: psychological morbidity in first year medical students. Medical education, 29(5), $337-341$. https://doi.org/10.1111/j.1365-2923.1995.tb00022.x

Ibrahim, A. K., Kelly, S. J., Adams, C. E., \& Glazebrook, C. (2013). A systematic review of studies of depression prevalence in university students. Journal of psychiatric research, 47(3), 391-400. https://doi.org/10.1016/j.jpsychires.2012.11.015

Ibrahim, M. B., \& Abdelreheem, M. H. (2015). Prevalence of anxiety and depression among medical and pharmaceutical students in Alexandria University. Alexandria Journal of Medicine, 51(2), 167-173. https://doi.org/10.1016/j.ajme.2014.06.002

Inam, S. N. B., Saqib, A., \& Alam, E. (2003). Prevalence of anxiety and depression among medical students of private university. Journal-Pakistan Medical Association, 53(2), 44-46.

Issa, B. A., Yussuf, A. D., Olanrewaju, G. T., Abiodun, O. A. (2014). Mental health of doctors in a tertiary hospital in Nigeria. Pan African Medical Journal, 19, 178. https://doi.org/10.11604/pamj.2014.19.178.3642

Jahrami, H., Sater, M., Abdulla, A., Faris, M.A., AlAnsari, A. (2019). Eating disorders risk among medical students: a global systematic review and meta-analysis. Eat Weight Disord, 24, 397-410. https://doi.org/10.1007/s40519-018-0516-z

Jahrami, H., Dewald-Kaufmann, J., Faris, M. A., AlAnsari, A. M. S., Taha, M., \& AlAnsari. N. (2020). Prevalence of sleep problems among medical students: a systematic review and meta-analysis. J Public Health, 28, 605-622. https://doi.org/10.1007/s10389-019-01064-6

Juma, K., Wekesah, F. M., Kabiru, C. W., \& Izugbara, C. O. (2020) Burden, Drivers, and Impacts of Poor Mental Health in Young People of West and Central Africa: Implications for Research and Programming. In: McLean M. (eds) West African Youth Challenges and Opportunity Pathways. Gender and Cultural Studies in Africa and the Diaspora. Palgrave Macmillan, Cham. https://doi.org/10.1007/978-3-030-21092-2_11

Khan, A. A., Sultan, A., \& Jan, F. A. (2014). Effects of perceived stressors and psychiatric morbidity on academic performance of university students. Journal Of Management Info, 4(1), 147-156.

Lovibond, P. F., \& Lovibond, S. H. (1995). The structure of negative emotional states: Comparison of the Depression Anxiety Stress Scales (DASS) with the Beck Depression and Anxiety Inventories. Behaviour research and therapy, 33(3), 335-343. https://doi.org/10.1016/0005-7967(94)00075-U

Mahajan, B. K. (2010). Methods in Biostatistics for Medical students and Research workers (7th ed., pp. 33-52). Jaypee Brothers Medical publishers (P) Ltd. New Delhi. 
Maj, M., Stein, D. J., Parker, G., Zimmerman, M., Fava, G. A., De Hert, M., ... \& Wittchen, H. U. (2020). The clinical characterization of the adult patient with depression aimed at personalization of management. World Psychiatry, 19(3), 269-293. https://doi.org/10.1002/wps.20771

Marcus, M., Yasamy, M. T., van Ommerem, M., Chisholm, D., Saxena, S., \& WHO Department of Mental Health and Substance Abuse (2012). Depression: A Global Public Health Concern. Geneva. World Health Organization. https://doi.org/10.1037/e517532013-004

Martin, M. (1997). Emotional and cognitive effects of examination proximity in female and male students. Oxford review of Education, 23(4), 479-486. https://doi.org/10.1080/0305498970230404

Moir, F., Yielder, J., Sanson, J., \& Chen, Y. (2018). Depression in medical students: current insights. Advances in medical education and practice, 9, 323. https://doi.org/10.2147/AMEP.S137384

Mojtabai, R., Olfson, M., \& Han, B. (2016). National trends in the prevalence and treatment of depression in adolescents and young adults. Pediatrics, 138(6). https://doi.org/10.1542/peds.2016-1878

Mutambara, J., \& Bhebe, V. (2012). An Analysis of the Factors Affecting Students' Adjustment at a University in Zimbabwe. International Education Studies, 5(6), 2012. https://doi.org/10.5539/ies.v5n6p244

NDU (2020). www.ndu.edu.ng. Official Niger Delta University website

Ngasa, S. N., Sama, C. B., Dzekem, B. S., Nforchu, K. N., Tindong, M., Aroke, D., \& Dimala, C. A. (2017). Prevalence and factors associated with depression among medical students in Cameroon: a cross-sectional study. BMC psychiatry, 17(1), 1-7. https://doi.org/10.1186/s12888-017-1382-3

Nwobi, E. A., Ekwueme, O. C., \& Ezeoke, U. E. (2009). Mental depression and coping strategies among medical students of University of Nigeria, Enugu campus. International Journal of Medicine and Health Development, 14(1).

Oku, A., Oku, O., Owoaje, E., \& Monjok, E. (2015). An assessment of mental health status of undergraduate medical trainees in the University of Calabar, Nigeria: a cross-sectional study. Open access Macedonian journal of medical sciences, 3(2), 356. https://doi.org/10.3889/oamjms.2015.068

Oladiji, J. O., Akinbo, S. R. A., Aina, O. F., \& Aiyejusunle, C. B. (2009). Risk factors of post-stroke depression among stroke survivors in Lagos, Nigeria. African Journal of psychiatry, 12(1), 47-51. https://doi.org/10.4314/ajpsy.v12i1.30278

Onyishi, M., Talukdar, D., Sanchez, R., Olaleye, A. O., \& Medavarapu, S. (2016). Prevalence of clinical depression among medical students and medical professionals: a systematic review study. Arch Med, 8, 6 . https://doi.org/10.21767/1989-5216.1000178

Pettersson, A., Boström, K. B., Gustavsson, P., \& Ekselius, L. (2015). Which instruments to support diagnosis of depression have sufficient accuracy? A systematic review. Nordic journal of psychiatry, 69(7), 497-508. https://doi.org/10.3109/08039488.2015.1008568

Pierceall, E. A., \& Keim, M. C. (2007). Stress and coping strategies among community college students. Community Coll J Res Pract, 31(9), 703-712. https://doi.org/10.1080/10668920600866579

Puthran, R., Zhang, M. W., Tam, W. W., \& Ho, R. C. (2016). Prevalence of depression amongst medical students: A meta-analysis. Medical education, 50(4), 456-468. https://doi.org/10.1111/medu.12962

Rice, K. G. (1992). Separation-individuation and adjustment to college: A longitudinal study. Journal of Counseling Psychology, 39(2), 203. https://doi.org/10.1037/0022-0167.39.2.203

Roh, M. S., Jeon, H. J., Kim, H., Han, S. K., \& Hahm, B. J. (2010). The prevalence and impact of depression among medical students: a nationwide cross-sectional study in South Korea. Academic Medicine, 85(8), 1384-1390. https://doi.org/10.1097/ACM.0b013e3181df5e43

Rotenstein, L. S., Ramos, M. A., Torre, M., Segal, J. B., Peluso, M. J., Guille, C., ... \& Mata, D. A. (2016). Prevalence of depression, depressive symptoms, and suicidal ideation among medical students: a systematic review and meta-analysis. Jama, 316(21), 2214-2236. https://doi.org/10.1001/jama.2016.17324

Schernhammer, E. (2005). Taking their own lives-the high rate of physician suicide. N Engl J Med, 352(24), 2473-2476. https://doi.org/10.1056/NEJMp058014

Sheehan, D. V., Lecrubier, Y., Sheehan, K. H., Amorim, P., Janavs, J., Weiller, E., ... \& Dunbar, G. C. (1998). The Mini-International Neuropsychiatric Interview (MINI): the development and validation of a structured diagnostic psychiatric interview for DSM-IV and ICD-10. Journal of clinical psychiatry, 59(20), 22-33. 
Singh, A., Lal, A., \& Singh, S. (2011). Prevalence of depression among medical students of a private medical college in India. Online Journal of Health and Allied Sciences, 9(4).

Sreeramareddy, C. T., Shankar, P. R., Binu, V. S., Mukhopadhyay, C., Ray, B., \& Menezes, R. G. (2007). Psychological morbidity, sources of stress and coping strategies among undergraduate medical students of Nepal. BMC Medical education, 7(1), 1-8. https://doi.org/10.1186/1472-6920-7-26

Thorley, C. (2017). Not By Degrees: Not by degrees: Improving student mental health in the UK's universities. IPPR: London, UK.

Van Niekerk, L., Scribante, L., \& Raubenheimer, P. J. (2012). Suicidal ideation and attempt among South African medical students. SAMJ: South African Medical Journal, 102(6), 372-373. https://doi.org/10.7196/SAMJ.5503

World Health Organization. (2001). Mental and neurological disorders. In Mental and neurological disorders (pp. 4-4). Retrieved from https://www.who.int/whr/2001/media_centre/en/whr01_fact_sheet1_en.pdf

World Health Organization. (2003). The world health report 2003: shaping the future. World Health Organization. Retrieved 14 November, 2011, from http:// www.who.int/whr/2003/en/

World Medical Association. (2004). Ethical principles for medical research involving human subjects. Declaration of Helsinki. https://doi.org/10.1001/jama.2013.281053

WHO. World Health Organization. Mortality Database Documentation: 1 May 2013, Update. WHO, 2013.

World Health Organization \& Calouste Gulbenkian Foundation. (2014). Social determinants of mental health. Geneva, World Health Organization, 2014

Zaid, Z. A., Chan, S. C., \& Ho, J. J. (2007). Emotional disorders among medical students in a Malaysian private medical school. Singapore medical journal, 48(10), 895.

Zoccolillo, M., Murphy, G. E., \& Wetzel, R. D. (1986). Depression among medical students. Journal of affective disorders, 11(1), 91-96. https://doi.org/10.1016/0165-0327(86)90065-0

\section{Copyrights}

Copyright for this article is retained by the author(s), with first publication rights granted to the journal.

This is an open-access article distributed under the terms and conditions of the Creative Commons Attribution license (http://creativecommons.org/licenses/by/4.0/). 